\title{
Self-rescue and Transformation of the Hotel Industry in China under the Epidemic
}

\author{
Yiguo Yu* \\ Yew Chung International School of Beijing, Beijing 100026, China \\ *Corresponding author: Yiguo Yu, ygh5008@126.com
}

\begin{abstract}
In order to minimize the impact of COVID-19 on entities such as the hotel industry, this article analyzes the development status of the hotel industry under the epidemic and suggests countermeasures for self-rescue and transformation, such as improving basic settings and optimizing management. These strategies provide ideas and suggestions to comprehensively improve the risk response of hotels and the implementation of sustainable development strategy.
\end{abstract}

Keywords: Epidemic situation; Hotel industry; Self-rescue and transformation

Publication date: October 2021; Online publication: October 29, 2021

\section{Introduction}

The sudden COVID-19 did not only disrupt the order of life, but also the pace of China's economic development. At the beginning of the Spring Festival in 2020, in order to actively respond to the epidemic, all provinces across the country successively issued the travel ban decree; in addition, enterprises, companies, and self-employed households were forced to shut down. In view of all these, they suffered an unprecedented impact. Many small and medium-sized companies and enterprises suffered serious losses and faced bankruptcy, especially the hospitality industry. The vertiginous drop in customer flow made it as one of the industries with the greatest losses. In order to adapt to this situation, the hotel industry had to stand on its own merits, speed up its transformation, and strive in the direction of self-help ${ }^{[1]}$.

\section{Difficulties faced by the hotel industry under the epidemic}

Under the influence of COVID-19, many enterprises had chosen to postpone the resumption of work, thus greatly reducing the travel task. This left the travel and tourism business, as the main source of income of the hotel industry, with great challenges. Although the severity of the epidemic varied across the country, hotels in most areas had to shut down in order to control the spread of the epidemic in accordance with the requirements of relevant government departments, the development of the epidemic, and the situation of the almost stagnant tourist sources. The outbreak of the epidemic not only brought irreparable losses to the hotel industry, but also lessons for the sustainable development of the hotel industry after the epidemic ${ }^{[2]}$. In the post-epidemic era, the business model of the hotel would undergo far-reaching changes, as shown in Figure 1. 


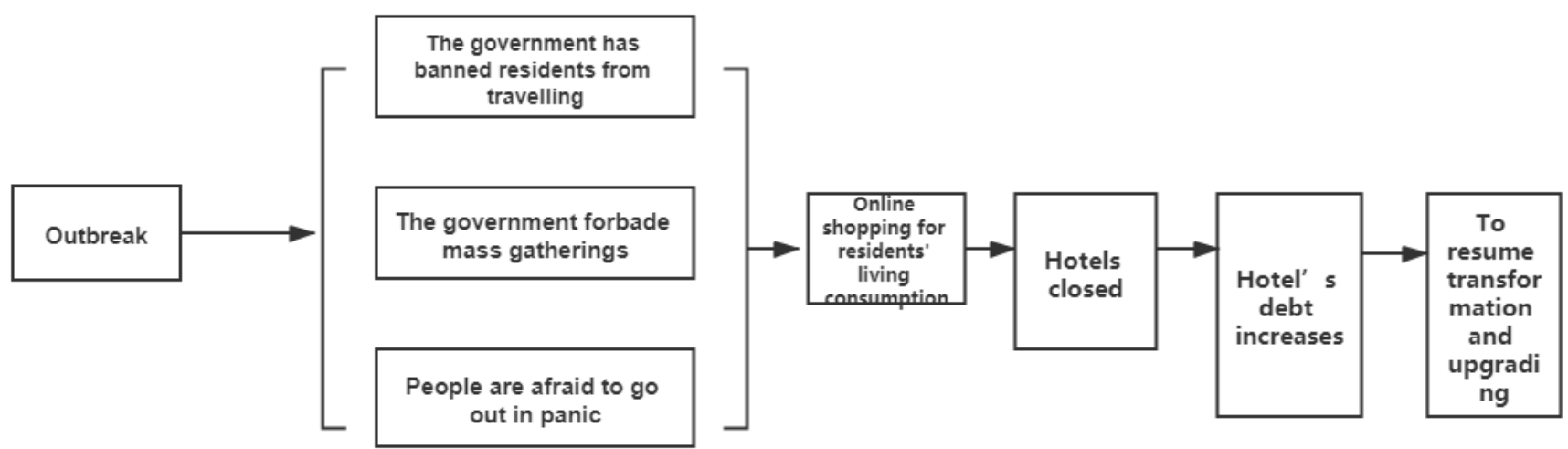

Figure 1. A logical model of the impact of the epidemic on the operation of traditional hotel industry

\subsection{Obvious brand effect and huge losses suffered by the hotel industry}

According to relevant statistics, in January 2020, the average occupancy rate of hotel rooms in China dropped sharply from $70 \%$ to $10 \%$ in the middle of the year. In February, the income per saleable house decreased by $80 \%$ compared with that in January. According to investigations and research on the occupancy rate of more than 600 hotels in 28 provinces, cities, and autonomous regions in China, the turnover loss of the hotel industry in only two months (January and February 2020) was more than 60 billion RMB. It has been expected that the annual revenue of the hotel industry would decline by $24 \%$ yearon-year and the loss would reach 130 billion RMB. During the epidemic period, the closure rate of domestic interlocking hotels was as high as $75 \%$ and that of independent hotels was $72 \%$. Due to rich experience in operation and strong anti-risk capability, international interlocking hotels took effective emergency measures; however, the closure rate was still as high as 50\% (Figure 2).

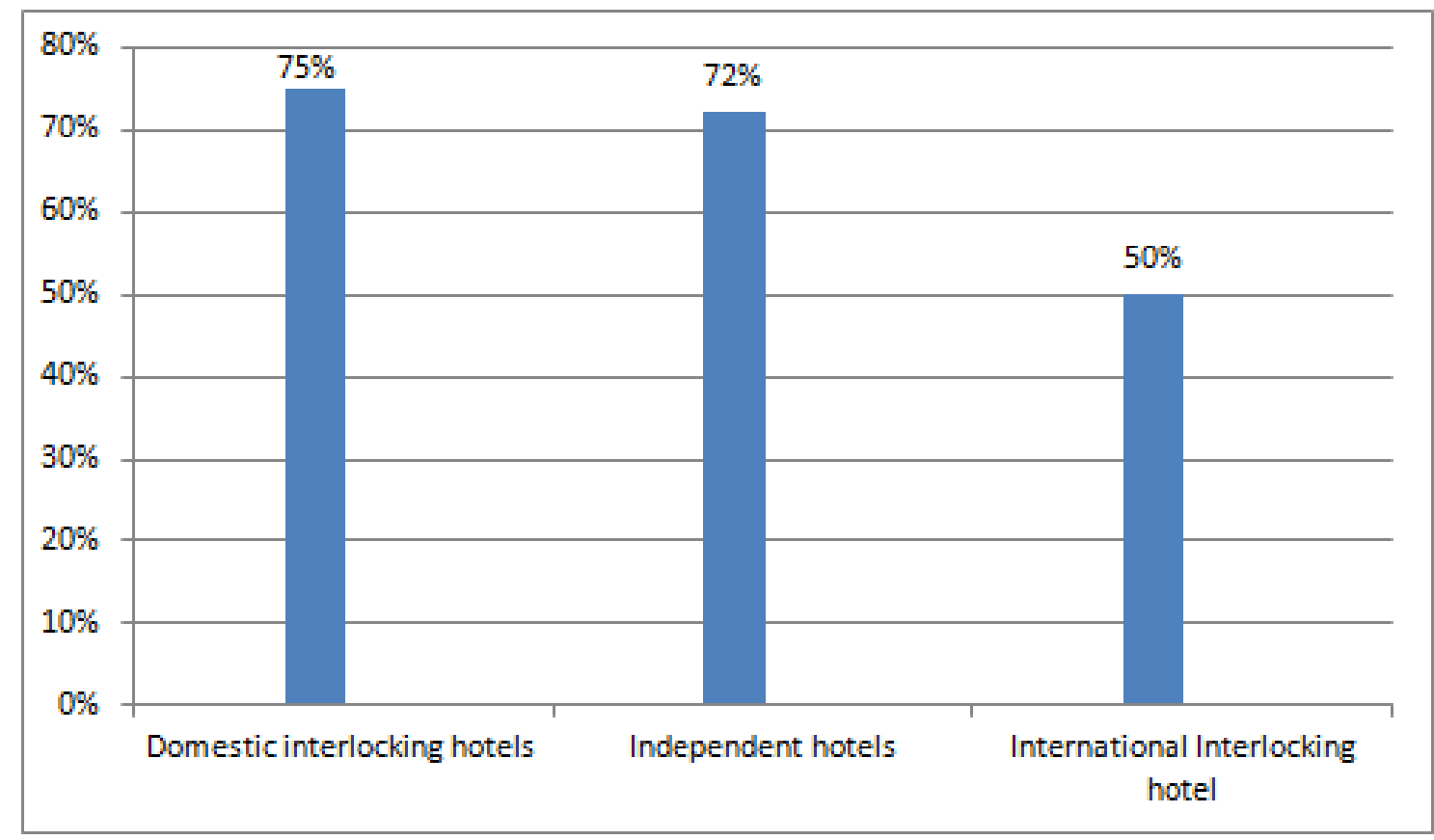

Figure 2. Closure rate of various types of hotels after the outbreak 


\subsection{Sharp decrease in customer flow and the profit margin is not directly proportional to the expenditure}

Under the influence of COVID-19, the occupancy rate of hotels gradually declined along with their revenue. However, in regard to the daily operation of hotels, the rents, utilities, asset management fees, labor costs, and other expenses did not decrease due to the spread of the epidemic. In addition, due to the demand of epidemic prevention work, hotels have been required to purchase various epidemic prevention equipment and materials, thus also consuming a large amount of money. All these expenses cannot achieve a positive proportional growth relationship with their operating profits. Many hotels have been operating at a loss, which is lower than that of some newly opened hotels. Under the dual pressure of expenses and huge bank interest, hotels are embarking on the road to bankruptcy.

\subsection{Capital on the sidelines and the difficulty in recovering from the broken initial capital chain}

Different from small companies and individual industrial or commercial households, during the early stage of establishment, in order to obtain a higher occupancy rate, many hotels must select the most prosperous area, use the most advanced hardware facilities to build the hotel, and put in a lot of effort to secure a position. All these inevitably lead to huge start-up funds. Under the influence of COVID-19, the business gap of several months and the low occupancy rate in the late-stage result in the difficulty to gain profits. Some hotels had to lay off their employees in order to save costs and expenses; some new hotels even had broken the capital chain due to the divestment of their allies and their early stage of business. These hotels are on the brink of bankruptcy and are suffering huge economic losses even though the economy is now recovering. Due to the huge losses in the early stage, they are unable to gain financial support even at this time. As a result, they have gradually lost the confidence to make a comeback ${ }^{[3]}$.

\section{Analysis on the self-rescue and transformation of the hotel industry under the epidemic}

One year after COVID-19 surfaced, the local economy is gradually picking up. People who have been staying at home for a long time can finally step out of their homes to work and consume; even the hotel industry is ushering in a new peak of development. In order to achieve better development, hotel management personnel should take into consideration on their exposed problems, actively strive in the direction of self-help, and walk in the path of transformation in order to effectively improve their response capacity in difficult times and their carrying capacity in prosperous times.

\subsection{Improving basic settings and enhancing the emergency capacity}

\subsubsection{Improving infrastructures}

In order to prevent the unavailability of infrastructures in the case of emergencies, the infrastructures of hotels should be improved and regularly maintained.

\subsubsection{Preparing emergency plans}

In the daily management of hotels, the employees' emergency response capacity should be strengthened in order to establish professional prevention and control teams in case of emergencies. In addition, all work pertaining to hotels should be efficiently carried out under the guidance of emergency plans. Secondly, it is crucial to pay close attention to the latest prevention guidance by the government and implement the guiding spirit to ensure that the emergency work has certain standardization, timeliness, and efficiency.

\subsection{Optimizing management and improving management efficiency}

Hotel managers should pay attention to the optimization of the management, redesign the management 
system in cases where the system does not actively promote the management, make up for the existing deficiencies, and increase the employment of professional expertise from the field of hotel management. These professionals should be given the upper hand in the management to display their professional skills, reposition the direction for the development of the hotel, and reduce the risk during difficult times through the construction of a high-quality command team to ensure that the hotel's economic benefits are not affected. In the post-epidemic era, the hotel industry should improve skills to professional division of labor and its management efficiency. For a long time, labor cost has accounted for a large proportion of the total cost. During the epidemic, the overloaded labor cost made it difficult for hotels to continue operating. In order to ensure that the service quality does not decline on the premise of low-cost investment, hotels should consider employee sharing. In addition, the outsourcing policy of certain products and services can also be implemented by hotels to provide their customers with better services through cooperation with third parties, thus reducing the costs while improving the benefits ${ }^{[4]}$.

\subsection{Optimizing products and services to effectively enhance market competitiveness}

Although the epidemic has been controlled in China, non-native infected people and asymptomatic infected people are still detected from time to time. Therefore, most people still choose to stay at home, and the antiepidemic work should not be abated during this period. Hotel managers should recognize this and provide customers with services other than accommodation services, such as catering and take-away services, so that consumers can have more diversified consumption experience through the hotel platform. The epidemic outbreak has motivated people to be more health conscious, thus having a further understanding about their own health. In the future, consumption concepts in terms of food, clothing, housing, and transportation would change greatly along with a more rational consumption choice and an upgraded basic living habit among consumers. In order to cater to consumers' needs to the greatest extent, the hotel industry should strive in the direction of innovating products, repairing customer relationships by means of excellent services, as well as promoting the development and transformation of hotels.

\subsection{Expanding hotels and increasing competitiveness}

During the epidemic period, in order for the hotel industry to have stronger survivability, it needs to establish a mature management system and become the leader of the industry. In addition, it can stand in for itself through mergers and acquisitions, integration and upgrading, as well as using management advantages to achieve greater competitive advantages.

\subsection{Adopting intelligent operation means to solve problems and adapting to the changes of the times}

Since the outbreak of the epidemic, offline work has been greatly affected, but online products have ushered in a new development peak in view of home office, online teaching, and other factors. Daily detection, prevention and control, tracking, and other work are also realized on a large scale by means of high-tech and information technology. Before that, in order to reduce the cost of investment and optimize business model, many traditional industries have comprehensively carried out the construction and application of information engineering so as to further improve the competitiveness of enterprises. The COVID-19 outbreak has demonstrated the power of the combination of internet of things (IoT) and artificial intelligence. Therefore, in the late stage of the epidemic, the hotel industry needs to break through the conventional way in order to reinvigorate itself and successfully realize transformation and upgrading. Referring to successful examples, the hotel industry should take into consideration of them: the use of artificial intelligence and means to carry out hotel management work; using the form of big data to establish data as well as an intuitive and controllable internal system; using technology intelligence to analyze and 
control the overall situation, find potential risks in time, and deal with them through efficient and feasible solutions. In short, artificial intelligence technology provides strong technical support for improving the efficiency of hotel management as well as realizing the optimization of hotel products and services. It is an important measure for hotels to build brand effect and promote changes ${ }^{[5]}$.

\section{Conclusion}

For the hotel industry, although the outbreak of COVID-19 has brought many difficulties and challenges, it lurks a great opportunity for development. In order to enable the hotel to quickly seize the market in the post-epidemic era, hotel managers should seize the opportunity for transformation and upgrading, reflect on themselves, determine the problems, and improve their brand effect through the implementation of a series of effective measures. At the same time, it is necessary to further improve the infrastructures, optimize the management mode and services, as well as apply intelligent operation means to improve the resilience of the hotel industry in tough times and in good times. Only in this way can the sustainable development of the hotel industry be guaranteed.

\section{Disclosure statement}

The author declares that there is no conflict of interest.

\section{References}

[1] Novel Coronavirus Pneumonia, 2021, Location of State-Owned Hotels Under the Background of New Crown Pneumonia Epidemic Situation. China Market, (04): 18.

[2] He D, 2021, Analysis on the Recovery Path of Hotel Industry in the Post Epidemic Era. Journal of Sichuan Tourism University, (03): 04.

[3] Li Y, Kang X, Yang Q, 2020, Understanding and Thinking of Hotel Catering Service in the Post Epidemic Era. Marketing Circle, (07): 24

[4] Wu H, 2020, Novel Coronavirus Pneumonia's Influence on China's Hotel Industry and Its Enlightenment. Journal of Heilongjiang Polytechnic (Comprehensive Edition), (05): 20.

[5] Li Y, 2020, Talking about the Transformation and Upgrading of the Hotel Industry Under the Background of COVID-19. Fujian Tea, (04): 25. 